Tohoku J. exp. Med., 1970, 101, 55-66

\title{
Some Factors Controlling Ureteral Peristalsis
}

\author{
Sergi Tsuchida \\ Department of Urology, Tohoku University School of Medicine, Sendai
}

\begin{abstract}
Tsuchrda, S. Some Factors Controlling Ureteral Peristalsis. Tohoku J. exp. Med., 1970, 101(1), 55-66 _ Electroureterograms were recorded primarily in dogs following severance of the extrinsic nerves, vascular ligation or mucosal anesthesia of the ureter in an attempt to clarify several factors possibly controlling the ureteral peristalsis. The results obtained may be summarized as follows: Complete blockage of the ureteral extrinsic nerves by means of renal autotransplantation resulted in practically no significant alterations in the pattern of electroureterograms. With dogs in which the renal artery was ligated for the purpose of studying the influence of the blood flow, no significant changes in the pattern of electroureterograms were observed. In contrast, severance of all blood vessels which supply the ureter was promptly followed by arrest of the peristaltic movement. In in vivo experiments a prompt cessation of ureteral peristalsis occurred in response to the application of 4 per cent xylocaine to the ureteral mucosa, whereas no significant changes occurred in peristaltic movement when the same solution was applied to the adventitia. An infliction of damage to the canine ureteral mucosa with $2.5 \%$ formalin resulted in permanent arrest of ureteral peristalsis. Thirty days afterwards, development of non-obstructive hydronephrosis was seen. Isolated canine ureters were subjected separately to the application of xylocaine to the mucosa and to the adventitia. The responses of the isolated ureters were identical, making a sharp contrast to the observations in the in vivo studies. _- ureteral electromyogram; ureteral peristalsis; xylocaine
\end{abstract}

Many reports have been published concerning whether ureteral peristalsis is under the control of the extraneous nerve or is due to the automatic action of the ureter itself, but opinions still diverge.

Studies published show that the ureter is supplied by a number of blood vessels including branches of the renal artery, funnicular artery, hypogastric artery and the superior and inferior vesical arteries. However, the influence of angiectomy of these vessels on the ureteral function has remained unstudied.

It has been suggested that the ureteral contractions are most probably prompted by the excitation of the muscle cell membrane which occurs as muscle fibers and becomes distended in response to a rise in intraureteral pressure generated by urine flow. Yet there seems to be no report dealing with the physiological significance of the ureteral mucosa which is in direct contact with the urine flow.

To study these problems we carried out electromyographic analysis of the ureteral movement in dogs after the complete blockage of the extrinsic ureteral

Received for publication, January 28, 1970. 
nerves by means of renal autotransplantation and after the ligation of blood vessels supplying the ureter.

In addition, we have made simultaneous recordings of urometrograms and electroureterograms following the application of xylocaine and formalin to the pelviureteral mucosa, adventitia and the muscularis, both in vivo and in vitro, to clarify the role of the mucosa of the urinary tract in the physiology of ureteral peristalsis. The present report describes the results of these studies.

\section{Materials and Methods}

In animal experiments a total of seventy adult mongrel dogs ranging in weight from 14 to $15 \mathrm{~kg}$ were used. In all cases the right ureter was used as a control and the left one as the experimental ureter. Clinical observations were made on the adults in whom the ureter on the unaffected side served as a control.

\section{Experiments in animals}

\section{1) Renal autotransplantation}

Renal autotransplantation was porformed on five dogs by cutting both the renal artery and vein close to the aorta and subsequently establishing end-to-end anastomoses by suturation, and by ureterocystostomy after cutting the lower ureter. Pelviureteral electromyograms and urometrograms were recorded in all five dogs before and after renal autotransplantation.

Recording of electromyograms of the renal pelvis was accomplished by bipolar extra. luminal lead using needle electrodes 250 microns in diameter which were inserted $0.5 \mathrm{~cm}$ apart on the serous surface along the longitudinal axis of the renal pelvis.

The electrodes used in ureterographic recordng were practically the same as those of the U-loop collar bipolar electrode ${ }^{1}$ described previously, although in the present study a polyethylene catheter with small holes bored several centimeters apart was used (Fig. 1). The use of this electrode allowed a smooth flow of urine from the ureteral movement into the bladder through the polyethylene catheter and virtually obviated the intraureteral retention of the urine which would influence the ureteral peristalsis. The electrode was inserted into the ureter either from the ureteral orifice transvesically or transpelvically by means of nephrostomy, and the electroureterography was performed.
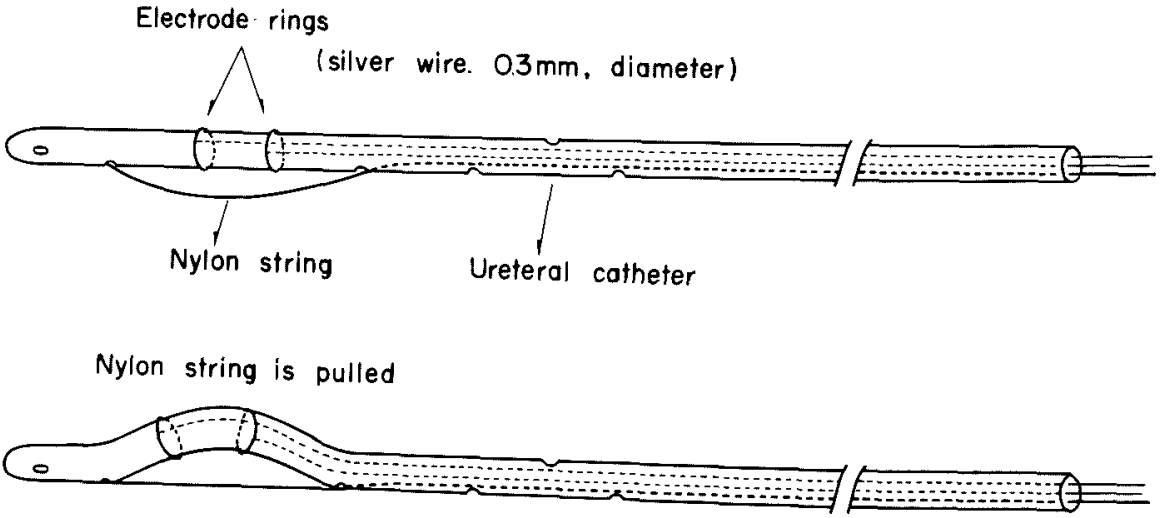

Fig. 1. Structure of modified "U-loop" collar eledtrode. 
For reoording urometrograms a ureteral catheter was inserted transvesically into the ureter or the renal pelvis, and its end was connected to a strain gauge.

\section{2) Vascular ligation}

Electroureterograms were recorded to study the effects of blood vessels supplying the ureter on ureteral function in a group of ten dogs. In five dogs the renal arteries and renal veins were ligated for the electromyographic recording of the ureter and in the remaining five dogs ligation was performed not only on the renal artery but on all other blood vessels supplying the ureter, i.e., the funnicular artery and vein, the hypogastric artery and vein, efc., and they were cut before entry into the ureter.

\section{3) Experiments on drug effects}

a) Xylocaine

In vivo experiments: For the application of xylocaine to the ureteral mucosa, and F-3 ureteral catheter was inserted in five nephrostomized dogs through the renal fistula into the renal pelvis so that the tip of the catheter approximated to the proximal end of the ureter. Effects of the surface anesthetic agent on the ureteral adventitia or muscle were also examined in another group of ten dogs by injecting xylocaine directly into the adventitia or into the muscularis of the exposed ureter.

In vitro experiments: In this series of experiments the middle portion of five isolated ureters $3 \mathrm{~cm}$ in length was used.

To ensure the action of xylocaine upon the ureteral adventitia, xylocaine was added at required concentrations to a $30 \mathrm{ml}$ bath of modified Krebs' solution, maintained constantly at $37^{\circ} \mathrm{C}$ and bubbled with $5 \%$ carbon dioxide and $95 \%$ oxygen, and isolated ureters were placed in this bath and fastened to supporting rods (Fig. 2).

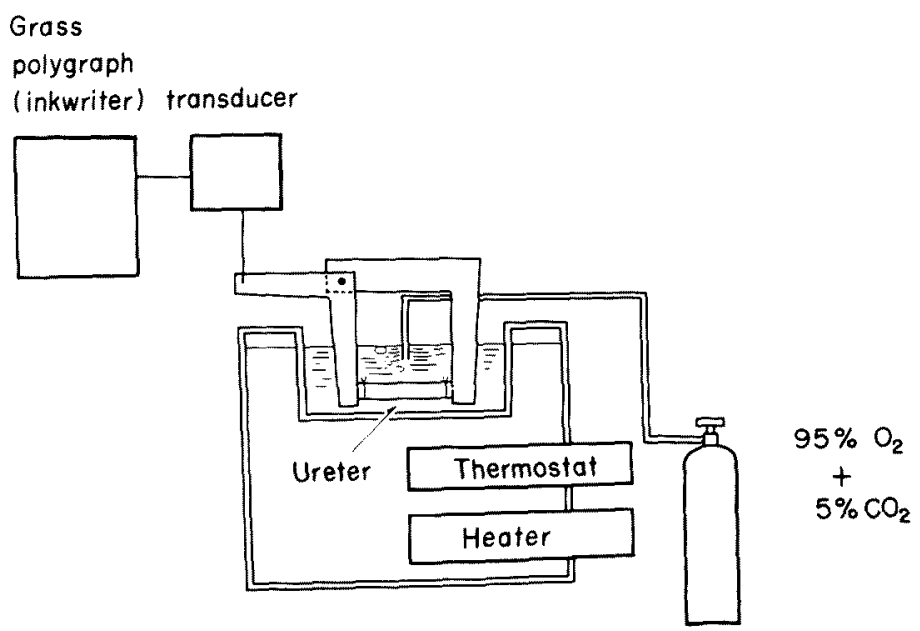

Fig. 2. Isometric recording method for studying influence of xylocaine on serous membrane.

Next, to examine the effect of xylocaine applied to the mucosa on the ureteral peristalsis, the isolated ureter was fitted on both ends with highly plastic silicone rubber tubes, size F-7, and modified Krebs' solution was perfused from one end of the tube to another at a constant speed in a $37^{\circ} \mathrm{C}$ bath. Xylocaine was added to the perfusate (Fig. 3). 


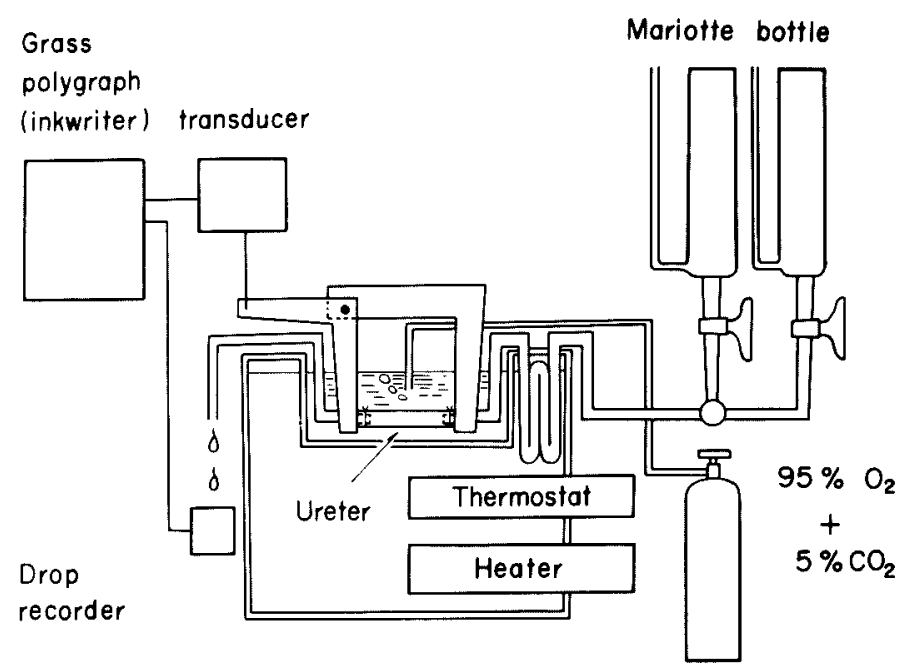

Fig. 3. Tsometric recording method for studying influence of xylocaine on ureteral mucosa.

b) Formalin

In vivo experiments were carried out with formalin in two groups of each ten laparotomized dogs. An F-6 ureteral catheter was inserted into the left ureter up to the level of the renal pelvis and $4 \mathrm{ml}$ of $2.5 \%$ or $5 \%$ formalin were gently infused through the catheter. The catheter was then removed from the ureter; another F-6 eatheter $4 \mathrm{~cm}$ in length was inserted with its tip about $3 \mathrm{~cm}$ inside the ureteral orifice, and the intravesical end of the catheter was sutured onto the vesical mucosal surface for immobilization. The indwelling catheter served as a protector against ureterorific stenosis which was often associated with ureteral formalin infusions.

The urinary bladder was then closed. Thirty days after the ureterograms, histological examinatins of the ureter and kidney were made.

\section{Clinical studies}

In five human subjects, apparently in health, an F-6 ureteral catheter was inserted through a cystoscope and $20 \mathrm{ml}$ of $4 \%$ xylocaine were infused gently into the renal pelvis. The electroureterogram was then examined.

\section{Results}

\section{1) Experiments in laboratory animals}

1) Electromyogram of normal canine renal pelvis, ureter and urometrogram. The preliminary electromyogram of the normal canine renal pelvis showed spike action potentials with regular discharge intervals of 4 seconds and an amplitude of $0.4 \mathrm{mV}$, whereas from the section of the ureter $5 \mathrm{~cm}$ distal to the pelviureteral junction, a coinciding emergence of action potentials, similarly regular, was recorded with the same discharge interval and an amplitude of $0.6 \mathrm{mV}$.

Regular urometrograms were recorded from the section of the ureter $10 \mathrm{~cm}$ distal to the pelviureteral junction. The systolic pressure ranged from 10 to 15 
$\mathrm{cmH}_{2} \mathrm{O}$, the resting pressure from 0 to $5 \mathrm{cmH}_{2} \mathrm{O}$, and the contraction wave interval from 3 to 4 seconds.

2) Electroureterogram of dogs following the renal autotransplantation. In autotransplanted dogs, urine flow from the ureteral orifice began in all instances about five minutes after the completion of transplantation, whereupon electromyograms of the ureter were recorded. As can be seen from Fig. 4, there was evidence of a slight prolongation of discharge intervals as compared with the preoperation state but the electroureterograms showed practically no alterations in the shape of waves, hence the similarly regular emergence of action potentials was observed.

\section{Preoperative recording}

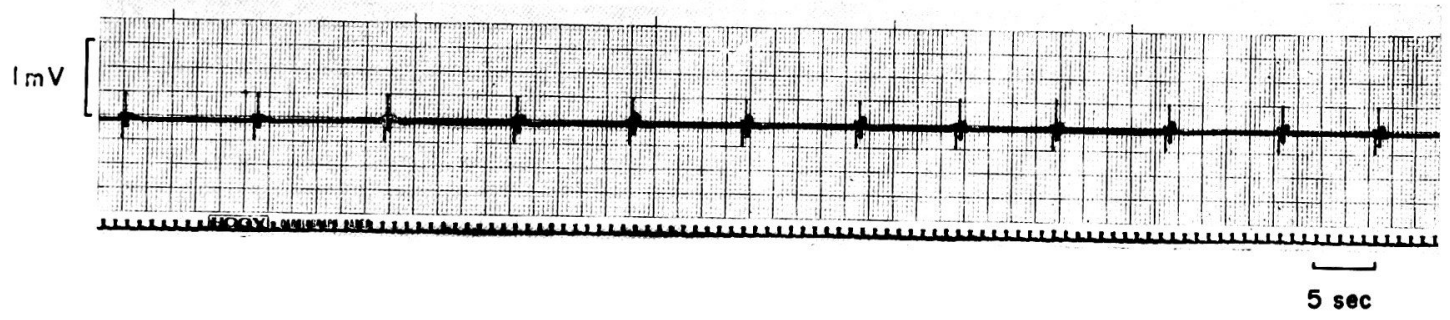

Postoperotive recording
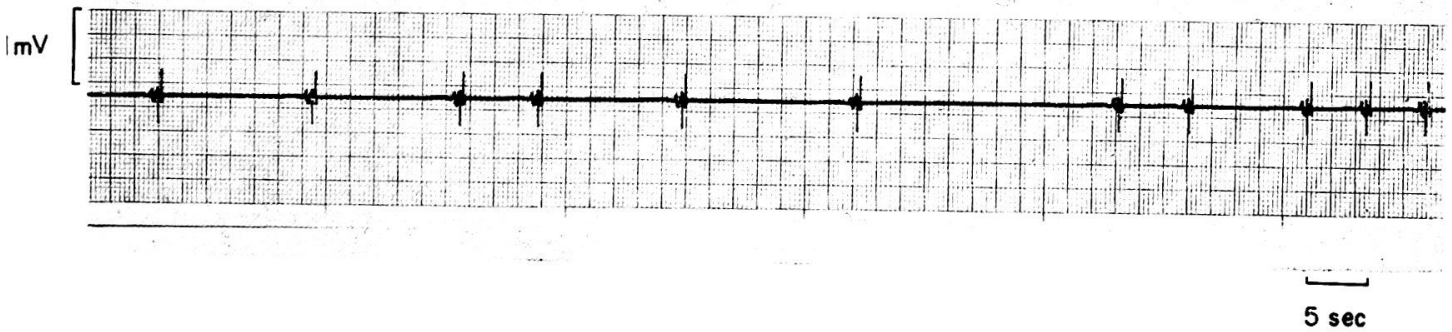

Fig. 4. Electroureterogram before and after autotransplantation of the kidney.

3) Electroureterogram of dogs after the cutting of blood vessels. Cutting of the renal artery and vein in dogs was immediately followed by the arrest of urine flow. However, peristalsis continued. There was evidence of a slight increase in discharge intervals, namely, from preoperative values of 4 to 5 seconds to postoperative values of 7 to 8 seconds, and the action potentials were in part irregular though no significant difference in amplitude was observed.

In other dogs in which only the renal artery and vein had been left intact, urine flow was not changed as compared with the control. Electroureterograms showed prolongation of discharge intervals in all cases by about 100 per cent occurring immediately after dissection of vessels. The prolonged discharge 
interval then gradually diminished to a fairly constant interval showing a 20 to 50 per cent increase over the level before dissection. Action potentials were partly irregular but they showed normal amplitude.

The cutting of all blood vessels supplying the ureter promptly resulted in a marked prolongation of discharge intervals and, in 4 to 5 minutes, the complete cessation of electric discharge.

\section{4) The effect of drugs}

a) Xylocaine

Application of xylocaine to the pelviureteral mucosa in vivo. Under the condition where the renal pelvis was disconnected from the ureteral lumen by pinching the pelviureteral junction with the fingers, the action potential disappeared 5 to 10 seconds following an infusion of 3 to $5 \mathrm{ml}$ of $4 \%$ xylocaine through a polyethylene tube via the renal fistula. This state, though it differed depending on the dose of xylocaine, usually lasted from 2 or 3 minutes to some 10 minutes. Thereafter action potentials of a very small amplitude and short discharge interval appeared regularly, gradually increasing in amplitude and returning to the pre-infusion state after 2 to 3 minutes. The urometrogram of the renal pelvis upon administration of xylocaine showed an increase in renal pelvic pressure from $5 \mathrm{~cm} \mathrm{H}_{2} \mathrm{O}$ to $15-20$ $\mathrm{cm} \mathrm{H}_{2} \mathrm{O}$ at the time of disappearance of action potentials and then a fall in pressure to below $5 \mathrm{~cm} \mathrm{H}_{2} \mathrm{O}$ at the time of the emergence of action potentials.

Electroureterograms were then studied in dogs given intraluminal infusions of xylocaine by two different methods separately but in the same dog. When 5 to $10 \mathrm{ml}$ of xylocaine solution was infused into the renal pelvis, without pinching, it undoubtedly entered into the ureteral lumen. Electroureterograms recorded in these dogs by retrograde insertion of the electrode into the ureter showed changes quite comparable to those observed with electropyelograms (Fig. 5). In response to an infusion of xylocaine solution, action potentials promptly disappeared, and a few minutes later this was followed by the emergence of waves small in amplitude. Urometrograms recorded by retrograde insertion of an F-3 polyethylene tube into the section of the ureter as in the case of electroureterography also showed subsidence in contraction waves following the infusion of xylocaine (Fig. 6).

The electrode was then inserted from a renal fistula to an upper position of the ureter and simultaneously retrograde insertion of a ureteral catheter was made. Electroureterograms were thus recorded while pinching the portion of the ureter above the tip of the inlying catheter and infusing a xylocaine solution through the catheter. Normal action potentials and contraction waves were recorded from the upper part of the ureter, whereas emergence of action potentials was not observed in the lower part of the ureter.

Application of xylocaine to the pelviureteral adventitia and tunica muscularis. Application of 4 per cent xylocaine to the renal pelvic and ureteral adventitia caused no significant changes. A further attempt was made to record the 

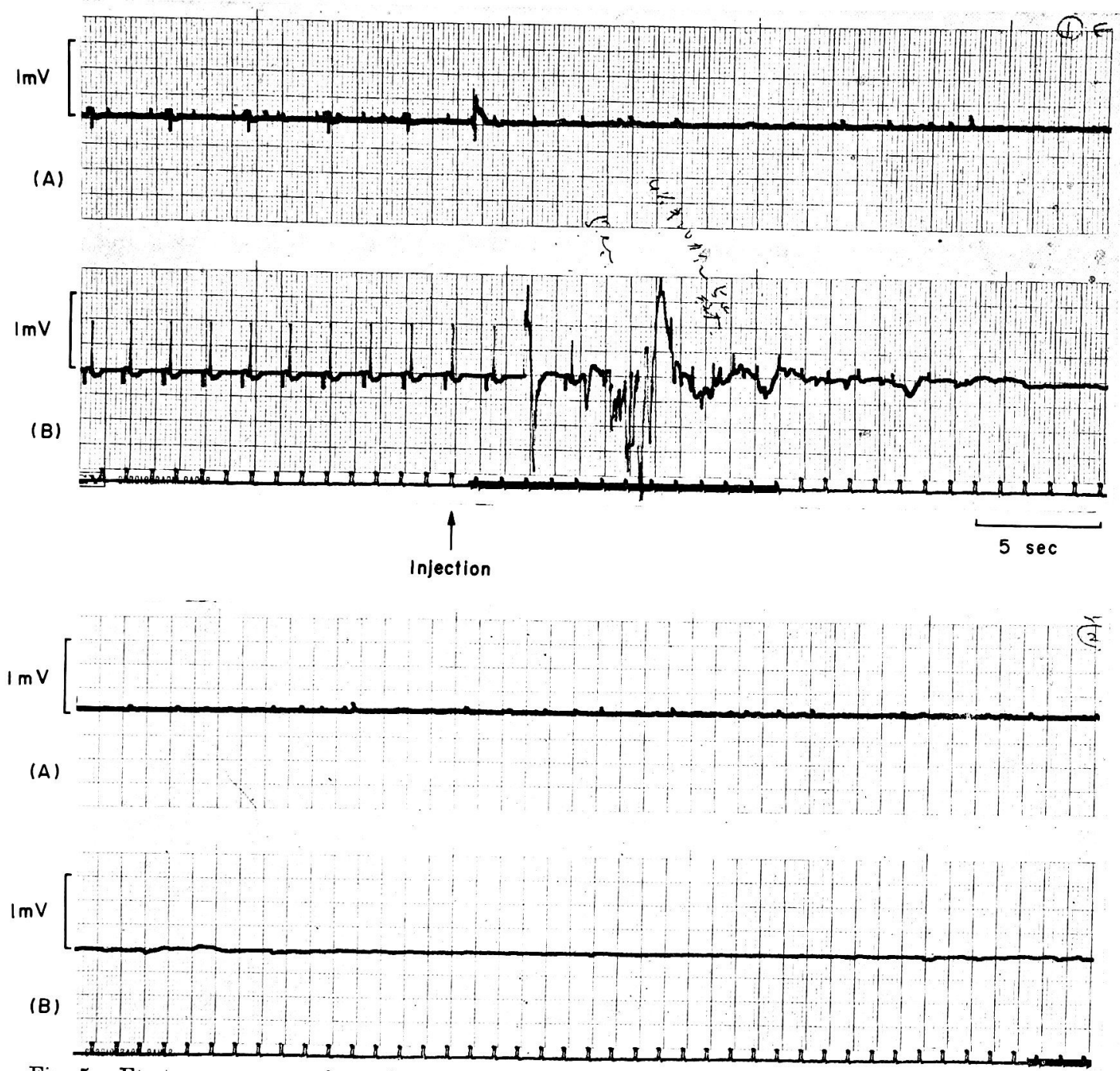
Fig. 5. Electromyograms of renal pelvis (A) and ureter (B) before and after the injection of $4 \%$
xylocaine into renal pelvis.

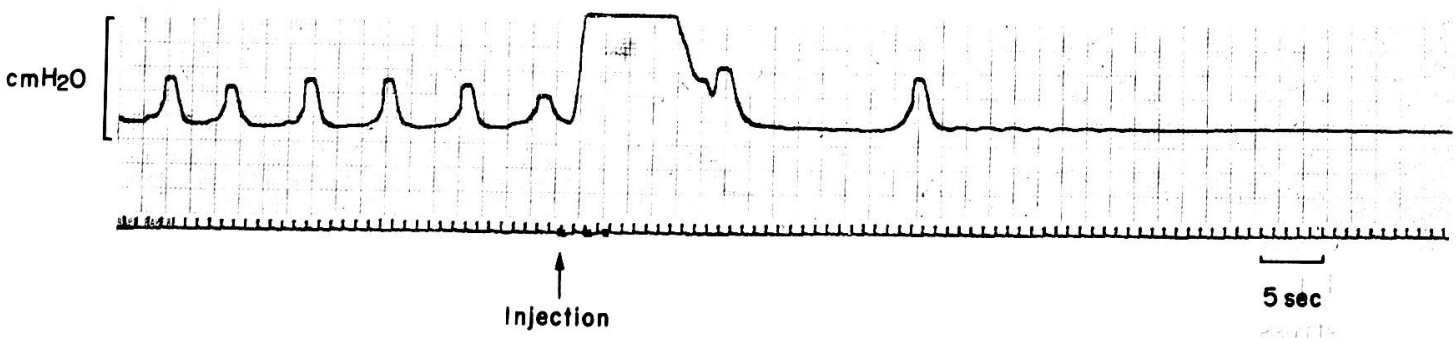

Fig. 6. Urometrogram before and after the injection of $4 \%$ xylocaine solution into the renal pelvis and ureter. 
electroureterogram by performing an injection of 4 per cent xylocaine at a dose of $0.5 \mathrm{ml}$ into the tunica muscularis of the ureters of ten dogs, but no changes in action potential were observed so far 2 to 3 minutes after the injection. The amplitude of the action potential, however, began to diminish by degrees at 2 to 3 minutes as the xylocaine solution injected began infiltrating the adjoining tunica mucosa, the action potential eventually dropping to $0.2-0.3 \mathrm{mV}$, or by $1 / 2$ to $2 / 3$, at 5 to 6 minutes after the injection. In 9 of the 10 dogs the action potential was restored to normal 7 minutes after the injection, whereas in the one remaining dog action potentials disappeared completely for 50 seconds 3 minutes after the injection. This duration of disappearance of action potentials was, however, extremely short in contrast to that observed after an intramucosal application of 4 per cent xylocaine.

Application of xylocaine to the ureteral mucosa and adventitia in vitro. The application of tensile force ranging from 1 to $2 \mathrm{~g}$ to isolated normal ureters gave rise to spontaneous excitation 10 to 20 minutes afterwards with a gradual increase in the contraction frequency developing 20 minutes after the onset of contraction to constant regular rhythmic contractions at a rate of 15 to 20 per minute each showing in polygraphic pattern diphasic or triphasic peaks.

To measure the effects of xylocaine upon the ureteral movement when applied to the mucous membrane, xylocaine was added to Krebs' solution perfusing the ureter through silicone rubber tubes. At a concentration of $10^{-6} \mathrm{~g} / \mathrm{ml}$ xylocaine caused no significant changes in the pattern of contraction waves. When the concentraton was raised to $10^{-5}$, there was in contrast a slight increase in contraction frequency, while the amplitude was decreased (Fig. 7A). When the xylocaine concentration was increased to $10^{-4}$, a substantial increase in frequency of contractions of narrow amplitude was brought about, followed shortly by complete subsidence in contraction.

Effects of adventitial application of xylocaine were also examined by adding xylocaine to a bath of Krebs' solution in which an isolated canine ureter was placed. $10^{-6}$ of xylocaine did not significantly alter the pattern of contraction. However, when the concentration was further raised to $10^{-5}$ to $10^{-4} \mathrm{~g} / \mathrm{ml}$ there occurred changes comparable to those observed after the mucosal application of xylocaine, namely, the ureteral contraction waves disappeared (Fig. 7B). All these findings indicate that the effects of xylocaine on the ureteral movement vary little by way of xylocaine application, i.e. application to the mucous membrane or to the serous membrane.

\section{b) Formalin}

Ten per cent formalin solution was injected into the renal pelvic lumen at doses ranging from 5 to $10 \mathrm{ml}$ and this caused deaths in all ten dog within 1 to 2 days, thereby indicating that $10 \%$ formalin solution inflicted a too strong stress not merely upon the pelviureteral mucosa but also upon the renal parenchyma. 
(A)

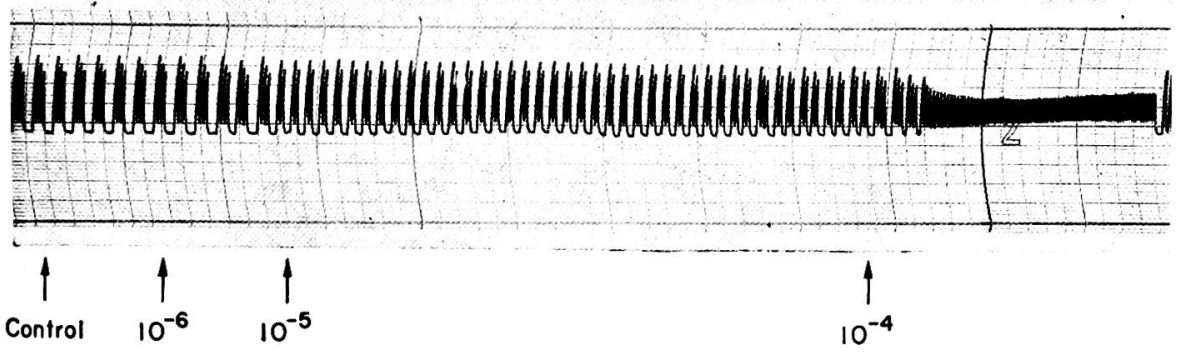

(B)
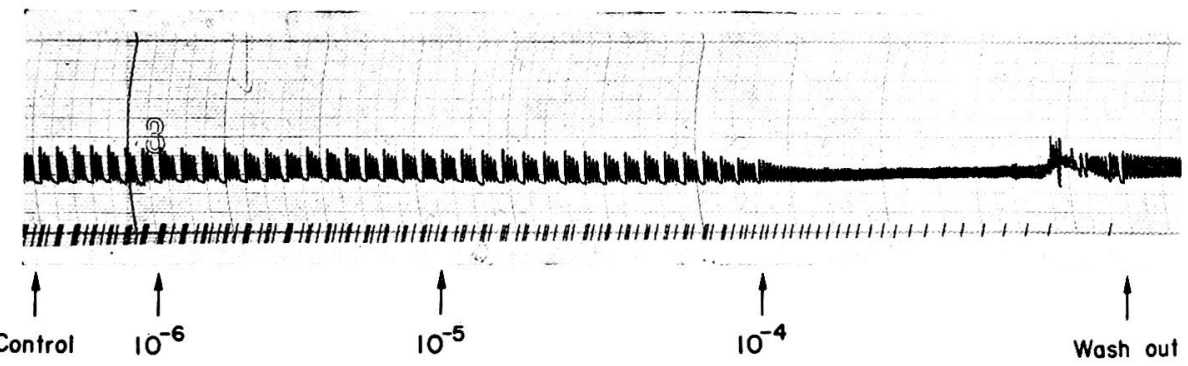

Fig. 7. Effect of xylocaine on mucosa (A) and serosa (B) of extirpated ureter.

Therefore, the concentration of formalin was reduced to 2.5 per cent in the following set of experiments with 10 dogs. Intrapelvic injection of $2.5 \%$ formalin gave rise to the complete disappearance of action potentials on electromyograms of the ureter which was taken from the section between 5 and $10 \mathrm{~cm}$ proximal to the orifice.

When electroureterograms were recorded upon cystostomy 30 days after infusion of $2.5 \%$ formalin, there was no evidence of emergence of action potentials. The pelvic wall of the left kidney was markedly distended with concomitant thinning of the renal parenchyma constituting acute hydronephrosis. Ureteral walls were slightly hyperplastic and there was a slight ureteral dilatation although there was no sign of ureteral cicatrical stenosis which might cause urinary obstraction (Fig. 8). In contrast, the findings for the right kidney and ureter were perfectly normal.

\section{2) Clinical studies}

Findings obtained through clinical studies were virtually consistent with those from the experiments in laboratory animals described above. Namely, there was a prompt disappearance of action potentials after the infusion of xylocaine solution, followed shortly afterwards by emergence of action potentials of small amplitude and later returning to the orginal state. Duration of the disappearance of the action potential, however, ranged from 40 seconds to $2-1 / 2$ minutes, hence apparently shorter than in laboratory animals. 


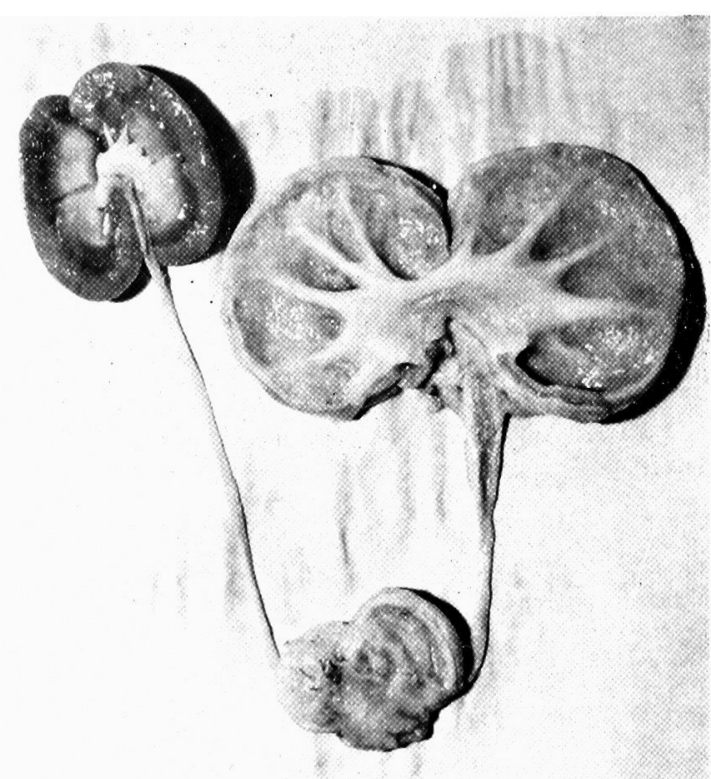

Fig. 8. Experimental hydrocephrosis after infusion of formalin solutio.. (left sidel).

\section{Discussion}

The presence of nerve cells within the ureteral structure has been well recognized. ${ }^{2-4}$ Distribution of the peripheral plexus that extends nerve fibers in various ways to the ureter has also been shown by Warton ${ }^{5}$ and by Ohgane. ${ }^{6}$ However, the question as to whether the ureteral peristalsis is generated by the nerve impulse or is solely dependent on ureteral autonomy are diverse despite a long history of discussion and, at present, not a few investigators deny the role of the extrinsic nerves in the genesis of the peristaltic movement. Melick et al. ${ }^{7}$ advanced the view that the ureteral peristalsis might be independent from the innervation of the ureter on the basis of a series of his study with pigs subjected to ureteral end-to-end anastomoses after severance of the ureter demonstrating that the severed ureter functioned in the same manner as before.

The conventional method for renal neurotomy for the purpose of studying the influence of innervation upon the ureter has been criticized in that it meant, as Quinby ${ }^{8}$ stated, only the cutting of nerve fibers surrounding the renal blood vessels and consequently it left some nerve fibers embedded in the wall of the blood vessels supplying the kidney. It was therefore not renal neurotomy in the true sense. In contrast, end-to-end anastomoses of the vessels were performed in the present study only after complete severance of the renal artery and vein and hence it may well be said that complete severance of the renal nerves was achieved. The possibility of the positive role of innervation in the genesis of ureteral movement cannot be totally denied at the moment since a series of recent studies published by Boyarsky et al., ${ }^{9}$ and Boyarsky and Labay ${ }^{10}$ suggest a nervous 
control of the ureteral movement. However, the absence of significant alterations in the electroureterographic pattern of the ureteral movement observed in the present study in dogs upon the cutting of the renal blood vessels indicates that the ureteral movement is only very slightly controlled by the nerve and, as revealed by the results of the previous study, depends upon automatic movement.

Reports concerning effects of blood flow on the ureteral peristalsis are few and previous studies of autonomic movement of the isolated ureter appeared to indicate that most probably ureteral movement is effected even without the blood supply. To our knowledge, the only study published is Hasegawa's electroureterographic observation of the ureter in animals with their renal blood vessels blocked by ligation. ${ }^{11}$ Hasegawa found that, in repsonse to ligation of the renal artery after renal neurotomy, urine flow ceased, whereas emergence of ureteral peristaltic discharge practically comparable to that of the preligature state continued. Simple cutting of the renal artery does not stop ureteral peristalsis because the renal pelvis and upper part of the ureter are also supplied by other vessels. Moreover, the lower portion of the ureter receives the blood supply through the branches of the inferior hypogastric artery and of the superior and inferior vesical arteries and these as well as the above mentioned may inevitably be auxiliary routes for blood supply. The results we obtained in dogs with their renal artery and vein ligated were consistent with those which have been described by Hasegawa," whereas we obtained evidence of complete arrest of ureteral peristalsis resulting from ligation of all arteries supplying the ureter including the renal artery. It may follow from this fact that the automatic movement of the ureter is maintained even in subjects with their renal arteries ligated, as long as blood flow to the ureter continues via other arteries to prevent the development of a hypoxic state.

It was found in the present investigation that both renal pelvic and ureteral mucous membranes showed very profound sensitivity to xylocaine in vivo; a prompt arrest of ureteral peristalsis occurred in response to an intrapelvic or intraureteral infusion while no significant alterations in the pattern of ureteral peristalsis were observed following application of xylocaine onto the serous membrane or into the tunica muscularis.

These experimental findings are not enough to elucidate the mechanism by which the ureteral peristalsis is generated within the ureteral mucosa, but suggest the presence of some sort of mechanism in the mucosa controlling peristaltic movement. This view is further supported by our previous study ${ }^{12}$ and by those other investigators ${ }^{13}$ which showed that changes in urine flow delicately affect the ureteral peristalsis.

A series of in vitro experiments with xylocaine on isolated ureteral preparations, unlike in vivo experiments, revealed no significant difference in the ureteral response between the application of the anesthetic agent to the mucosa and that to the adventitia. The cessation of blood flow resulting from the ureteral extraction may now be attributed at least in part to the above difference between the in vivo and in vitro experiments. As described above, there are a number of 
arteries that supply the ureter, and it has been shown by De Sousa ${ }^{14}$ through his microangiographic studies that a fairly large blood vessel runs longitudinally in the adventitiz of the ureter, giving its branches transversally to the tunica muscularis and the mucosa and finally forming the plexus within the submucosa. This indicates that the adventitia receives a more abundant blood supply than the mucosa when the ureter remains in vivo. It may not be impossible, in this context, to associate this fact with the demonstrably important role of the mucosa in the genesis of ureteral peristalsis.

In the present study we succeeded in producing hydronephrosis in dogs by arresting ureteral peristalsis upon intrapelvic or intraureteral infusion of 2.5 per cent formalin, a drug which exerted sustained toxic effects on the mucosa. This is undoubtedly important in that the technique entirely differs from the conventional one where hydronephrosis is induced by producing partial stenosis of the ureter and furthermore in that this fact provides the evidence of the paramount role of ureteral peristalsis in the movement of the urine from the renal pelvis down into the bladder.

\section{References}

1) Tsuchida, S. \& Kimura, Y. Electromyography of the ureter through cystoscope. Tohoku J. exp. Med., 1964, 83, 1-10.

2) Engelmann, T.W. Zur Physiologie des Ureter. Pflügers Arch. ges. Physiol., 1869, $2,243-293$.

3) Hryntschak, T. Beiträge zur Physiologie des Ureters. I. Zur Harnleiterantomatie. Pflügers Arch. ges. Physiol., 1925, 209, 542-561.

4) Dogiel, A. Zur Kenntniss des Nerven der Ureteren. Arch. mikroskop. Anat., $1878,15,64-78$.

5) Warton, L.R. Innervation of ureter. J. Urol., 1932, 28, 639-773.

6) Ohgane, R. Experimental and histological studies of the innervation of the ureter. Fukushima-Igaku Zasshi (Jap.), 1960, 10, 675-690.

7) Melick, W.F., Naryka J.J. \& Schmidt, J.H. Experimental studies of ureteral peristaltic pattern in the pig, II. Myogenic activity of the pig ureter. J. Urol., 1961, 86, 46-50.

8) Quinby, W.C. The function of the kidney when deprived of its nerves. J. Exp. Med., 1916, 23, 535-548.

9) Boyarsky, S., Kirshner, N. \& Labay, P. Catecholamine content of the normal dog ureter. Invest. Urol., 1966, 4, 97-102.

10) Boyarsky, S. \& Labay, P. The effect of dichloroisoproterenol, a $\beta$-adrenergic blocker, on ureteral function. Invest. Urol., 1966, 4, 1-8.

11) Hasegawa, K. Electromyographic study on the dog's ureter under dissection of the nerves innervating kidney a:d ureter. Tohoku Igaku Zasshi (Jap.), 1961, 64, 365-736.

12) Tsuchida, S. Computer analyses of urometrographic and electroureterographic data on the ureteral function at various urine flow rates. Tohokw. J. exp. Med., 1959, 97, 297-310.

13) Kiil, F. \& Kjekshus, J. The Physiology of the Ureter and Renal Pelvis. Proc. 3rd. Congr. Nephrol., Vol. 2, Karger, New York, 1967, pp. 321-335.

14) De Sousa, L.A. Microangiographic aspects of the ureter. J. Urol., 1966, 95, 179-183. 